\title{
Holmium-YAG laser for gall stone fragmentation: an endoscopic tool
}

M J K Blomley, D A Nicholson, G Bartal, C Foster, A Bradley, M Myers, W Man, S Li, L M Banks

\begin{abstract}
A systematic review of the $2 \cdot 1 \mu$ holmiumYAG laser for gall stone lithotripsy was undertaken. This infrared laser, which can be used endoscopically and percutaneously, has safety advantages over other lasers and has potential as a general purpose vascular and surgical tool. Twenty nine gall stones (mean mass $1.3 \mathrm{~g}$ ) were fragmented in vitro using pulse energies of 114 to $159 \mathrm{~mJ} /$ pulse at $5 \mathrm{~Hz}$ with a 0.6 $\mathrm{mm}$ fibre, while being held in an endoscopy basket. All stones were successfully fragmented, requiring an average of 566 pulses with a $5 \mathrm{~Hz}$ pulse repetition frequency. The number of pulses required increased with gall stone size and mass $(p<0.01)$, and decreased with both pulse energy $(p<0.01)$ and operator experience $(p<0 \cdot 05)$. The biochemical content of the stone did not significantly affect the number of pulses needed. The potential hazard of the laser to the biliary endothelium was investigated. At the pulse energies used, five pulses at close contact penetrated into the serosa of fresh gall bladder wall. No damage was seen when two pulses were fired. This laser shows considerable promise in gall stone lithotripsy. Until further safety data are available, however, its use with endoscopic vision is advised. (Gut 1995; 36: 442-445)
\end{abstract}

Keywords: holmium-YAG laser, endoscopic gall stone fragmentation.

Department of Diagnostic Radiology, M J K Blomley D A Nicholson G Bartal L M Banks

Histopathology, C Foster

Medical Physics, A Bradley M Myers

and Surgery, W Man

Hammersmith Hospital, London

Correspondence to: Dr M J K Blomley, Department of Diagnostic Radiology, Hammersmith Hospital, Du Cane Road, London W12.

Accepted for publication 20 June 1994
The holmium-YAG laser is a pulsed, solid state laser which produces light at a wavelength of $2 \cdot 1 \mu$, in the near infrared region. It is compatible with a conventional silica fibre, making it suitable for both endoscopic and percutaneous use. It also has a high absorbtion coefficient in water ${ }^{1}\left(3 \mathrm{~mm}^{-1}\right)$, suggesting a definite safety advantage over other lasers that have been used in gall stone lithotripsy. It has shown particular promise in vascular intervention, but may also emerge as a useful tool for the general and specialist surgeon. Owing to the high capital costs of any clinical laser system, there are clear advantages in using a laser that has more than one application, and it was this aspect as well as the theoretical advantages that prompted our investigation.

While laser lithotripsy of gall stones has attracted much interest at other wavelengths, there has been little detailed investigation of the use of the holmium laser to fragment gall stones.

\section{Methods}

Twenty nine relatively large gall stones were collected from surgical or cadaveric sources and stored in normal saline for a maximum of three months before fragmentation. They were all analysed physically (for mass, volume, and density) and radiologically before fragmentation. Radiological analysis was conducted by computed tomography (CT) of the stones immersed in saline, using contiguous $2 \mathrm{~mm}$ sections. The machine used was a Somatom Plus (Siemens Medical Systems, Erlangen, Germany). Using the CT data, mean and regional $x$ ray attenuation values were expressed in Hounsfield units. The stones were also classified on their CT morphology as being either uniform, rimmed (where a high density rim surrounded a low density core), or mixed.

The laser used was a prototype Laser1-2-3 produced by Trimedyne Inc (Irvine, California, USA). A $0.6 \mathrm{~mm}$ flexible silica fibre was used at three energy settings of 114,132 , and $159 \mathrm{~mJ}$ per pulse. Pulse repetition frequency was standardised at $5 \mathrm{HZ}$.

Preliminary calibration studies were performed. The power emerging from the fibre tip was calibrated by recording power readings on a laser power meter (Trimedyne Inc) over a range of pulse energies. This was done at a variety of distances from the power meter. All readings were taken in triplicate and averaged. Charts were prepared enabling subsequent calibration of the fibre. This preliminary work also enabled us to confirm the manufacturer's claim that any deterioration of fibre tip performance could be corrected by cleanly sectioning the distal $0 \cdot 5-1 \mathrm{~cm}$ of fibre with a glass cutting knife.

Before and after each use of the laser, the power emerging from the fibre tip could be

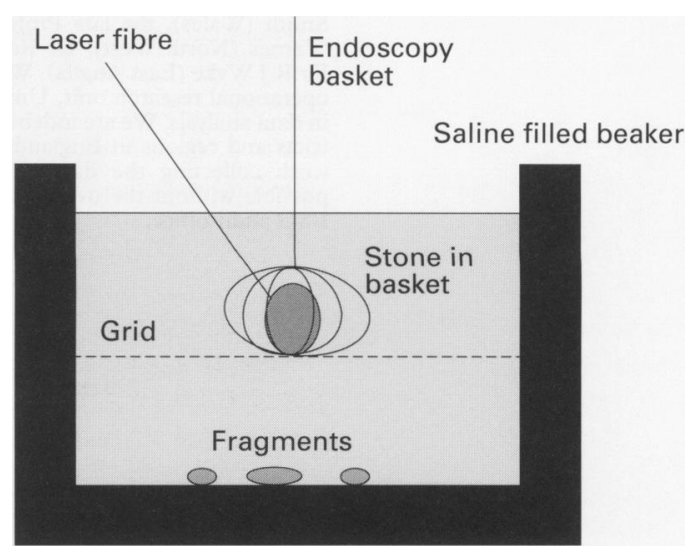

Figure 1: Fragmentation method. 


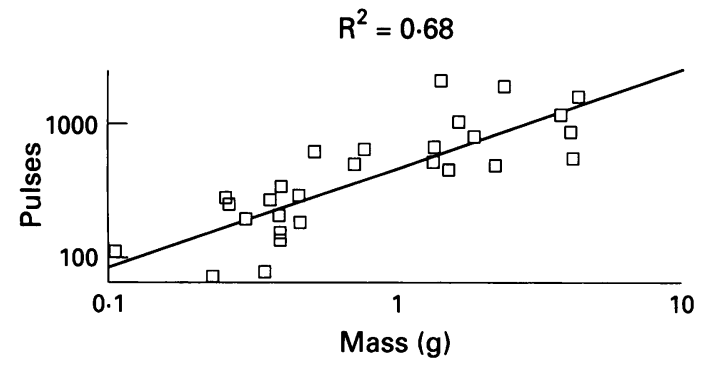

Figure 2: Scatter plot of gall stone mass in relation to the number of pulses required for fragmentation.

checked using these calibration charts. We recorded the power output when the fibre tip was held at a standard distance $(13 \mathrm{~cm})$ from the face of the power meter. Results were taken in triplicate and averaged. We were thus able to ensure that the fibre produced a satisfactory power output. This was defined as being within $10 \%$ of the previously calibrated optimum for the pulse energy setting used. Finely sectioning the distal fibre tip, as described, was performed if necessary. The stones were then fragmented by holding them in a standard endoscopy basket immersed in a saline bath over a $4.5 \mathrm{~mm}$ mesh. Fragmentation was performed by holding the fibre-directed laser beam against the side of the stone. This was deemed complete when all the fragments had fallen through the mesh (see Fig 1).

The basket was tightened progressively as lasing proceeded. In general, the stone fragments either remained in the basket until they were small enough to fall through the mesh or - particularly with the soft cores of some stones - disintegrated completely. Occasionally, larger particles needed to be collected a second time in the basket for complete fragmentation. Further technical aspects of the fragmentation process are described below in the discussion section. The order in which the stones were fragmented was recorded to investigate if there was an improvement with experience.

The reduction in fibre tip performance after stone lithotripsy was studied. The proportional decline in power output after each lithotripsy was correlated against the number of pulses used. As control, the laser was fired 3000 times at $5 \mathrm{~Hz}$ in air, saline, and bile and the power output recorded every 500 pulses.

After fragmentation, the stone contents were extracted from the saline by filtration, weighed, and analysed for calcium, cholesterol, and bilirubin content. The gall stones were classed as cholesterol stones (over $80 \%$ cholesterol), mixed stones (between $25 \%$ and $80 \%$ cholesterol), and pigment stones (under $25 \%$ cholesterol).

Safety aspects were investigated. Nine portions of three fresh human gall bladders obtained at cholecystectomy were lased at close contact while in a saline bath. The same $0.6 \mathrm{~mm}$ fibre was used, and calibration was performed as before. Two, five, and 10 pulses were used at the same three energy settings: 114,132 , and $159 \mathrm{~mJ}$ per pulse. After lasing, the tissues were immediately fixed in neutral buffered formol saline $(10 \% \mathrm{w} / \mathrm{v}, \mathrm{pH} 7 \cdot 4)$ for 12 hours. Thereafter the specimens were divided into slides $0.4 \mathrm{~cm}$ in width and processed into paraffin wax before being blocked and sectioned 'on edge'. After staining with haematoxylin and eosin and Masson's trichrome, the sections were examined by an experienced hepatobiliary pathologist.

\section{STATISTICAL ANALYSIS}

Statistical analysis was performed using Statview (BrainPower Software, Calabasas, California, USA) with advice from a medical statistician. Unless stated otherwise, analysis was performed using either simple regression (where $t$ values are quoted based on the regression, against a null hypothesis that $\mathrm{R}^{2}=0$ ) or stepwise multiple regression (where a new variable was included if the $p$ value for the partial $F$ value was $<0.05$ ).

\section{Results}

The mean gall stone mass was $1.26 \mathrm{~g}$ (range $0 \cdot 11-4.3 \mathrm{~g})$, mean volume was $1.21 \mathrm{~cm}^{3}$ (range $0 \cdot 1-4 \cdot 1 \mathrm{~cm}^{3}$ ), and mean density $1 \cdot 16$ $\mathrm{gcm}^{-3}$. All stones were fragmented, requiring a mean of 566 pulses (range 33 to 2032). A multiple regression analysis showed that the number of pulses needed increased with gall stone mass ( $<<0.01)$ (see Fig 2$)$ and decreased with pulse energy $(p<0.01)$.

A multiple logarithmic regression analysis of the number of pulses against gall stone mass and pulse energy yielded beta coefficients of 0.82 (95\% confidence intervals (CI) 0.66 , $0.98)$ and $-2.6(95 \% \mathrm{CI}-4.0,-1.3)$ respectively, with an $\mathrm{R}^{2}$ of 0.83 . This suggests that $83 \%$ of the variation in fragmentation effort is explained by variations in gall stone mass and pulse energy. Fragmentation effort increases approximately as mass to the power 0.8 and decreases as pulse energy to the power $2 \cdot 6$.

Using the multiple regression model and after allowing for stone mass and pulse energy, there was a significant inverse association $(p<0.05)$ between the order in which the stone was fragmented and the number of pulses needed for fragmentation. This suggests a benefit from improved technique.

Seventeen out of $29(59 \%)$ of our gall stones were cholesterol stones (over $80 \%$ cholesterol) and there were $12(41 \%)$ mixed stones (between $25 \%$ and $80 \%$ cholesterol). There were no pigment stones in our sample, reflecting the fact that we deliberately tried to collect larger stones. No significant association between biochemical content and the number of pulses required to fragment the gall stones was seen, even when other key variables (mass and pulse energy) were allowed for using a multiple regression analysis. Note, however, that in three cases the weight of stone material analysed was under $70 \%$ of the originally assayed stone weight. The data from these stones was not entered into the multiple regression analysis.

No significant associations were seen when the mean, or regional attenuation, or morphology on CT was correlated with the number of pulses required for fragmentation. This was 


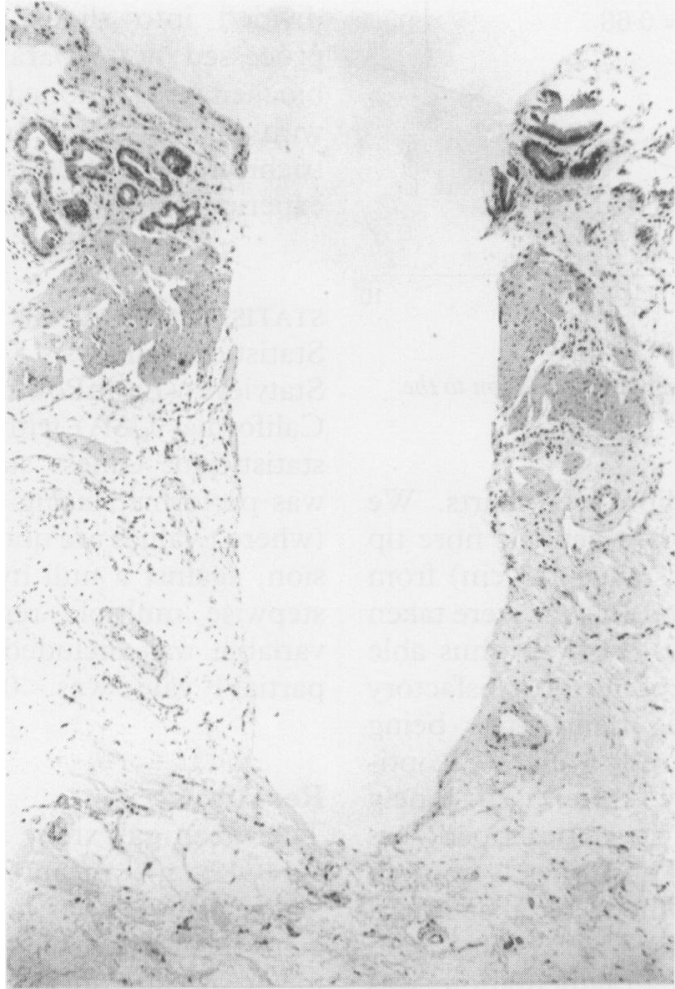

Figure 3: Section of gall bladder wall containing a cavity produced by 5 pulses at $114 \mathrm{mf} / \mathrm{pulse}$. The cavity extends through the mucosa and muscularis to penetrate the underlying serosal connective tissue to the level of the periserosal adipose tissue. The margins of the cavity are clean with no photothermic effects visible (haematoxylin and eosin, magnification $\times 60$ ).

the case again even when associations with other dependent variables were allowed for using multiple regression.

Fibre tip degradation was a considerable problem, with a variable but significant ( $\mathrm{p}<0.05 ; t$ test based on a simple regression) reduction in power output after repeated use of a fibre. A mean $22 \%$ reduction in power output per 1000 pulses of stone lithotripsy was observed. As control, no significant reduction was observed when the same fibre was fired for 3000 pulses in air, saline, bile, or other media with no stone present.

Of the nine portions of human gall bladder lased, no damage was apparent when only two pulses were used. With five pulses, penetration into the serosa was seen at all energy settings (Fig 3). With the use of 10 pulses, significant photothermic damage was observed (Fig 4). In all cases a narrow zone of thermal damage was observed.

\section{Discussion}

Most common duct calculi can be treated endoscopically or percutaneously, but a minority (about $10 \%$ ) resist conventional therapy. Moreover, all the accepted non-surgical treatments have their disadvantages. Endoscopic sphincterotomy carries a significant morbidity and mortality, the formation of a percutaneous tract takes weeks, and extracorporeal shockwave lithotripsy (ESWL) generally requires a sphincterotomy and a general anaesthetic. The possibility of effectively and safely fragmenting calculi via a flexible laser fibre has clear attractions. Both the $1.06 \mu$ neodynium-YAG and pulsed dye lasers have been used with success. ${ }^{2-7}$ Although a relatively new laser type, the $2 \cdot 1 \mu$ holmium laser may have theoretical safety advantages over other laser types. Its absorbtion coefficient in water $\left(3 \mathrm{~mm}^{-1}\right)$ is substantially higher; water energy absorbtion is over a hundred times that of the neodynium laser. ${ }^{8}$ We have confirmed that the holmium laser is indeed highly attenuated by bile; its effective penetration depth from an immersed fibre tip is between 0.12 and $1.8 \mathrm{~mm}$ depending on technical factors. ${ }^{9}$

There has been little published on the potential of this laser type for gall stone lithotripsy. Johnson et al have compared a similar laser (the $2 \cdot 15 \mu$ thulium-holmiumYAG laser) with ultrasound and ESWL but confine themselves to quoting a range of fragmentation times. ${ }^{10}$ Spindel et al have also shown that the holmium laser can fragment gall stones and suggest that fragmentation does not depend on the stone type. They were unable to show a clear relationship between fragmentation effort and energy delivery, however, and also assume the number of pulses needed increases linearly with mass.

We were encouraged to find that all stones could be fragmented. Given a $5 \mathrm{~Hz}$ pulse repetition frequency, this took an average of just under 2 minutes ( 113 seconds) of lasing, with a range of between 6 seconds (33 pulses) and 7 minutes (2032 pulses). As described below, this was best achieved with multiple short bursts of lasing with pauses for debris to clear.

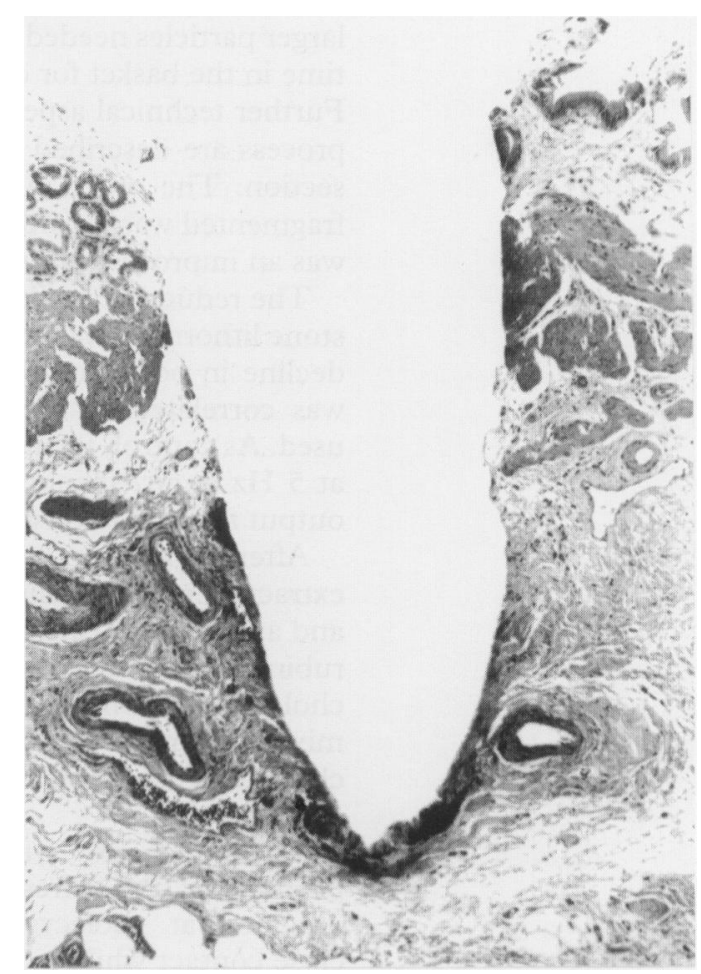

Figure 4: Gall bladder mucosa containing a cavity produced by 10 pulses at $160 \mathrm{mf} / \mathrm{pulse}$. The cavity extends for a distance through the mucosa, producing similar appearances to that produced by 5 shots at $114 \mathrm{mf} / \mathrm{pulse}$. Although the margins of the cavity are clean, however, some coagulation of connective tissue is revealed by special staining techniques at the cavity base, indicating local photothermic damage. (Masson's trichrome, magnification $\times 60$.) 
With reference to the basket, preliminary work established that effective immobilisation of the calculus was essential. Without this, the stone moved freely in response to the laser pulses. We would therefore recommend that calculi were immobilised in an endoscopic basket.

An independent association with operator experience was seen in this study. Three practical points were felt to explain much of the improvement with technique. Firstly, a small separation (approximately $0.5-1 \mathrm{~mm}$ ) of the fibre tip from the target helped fragmentation. This effect has been described in the context of salivary stone laser lithotripsy and is thought to be due to micro-cavitation. ${ }^{12}$ Secondly, the structural integrity of many of the larger stones was dependent on their hard rims, and selective lasing of the shell, rather than the softer cores, of these gall stones speeded disintegration. Thirdly, a significant amount of debris was generated by lithotripsy, particularly when lasing the softer cores of stones. This obscured visualisation.

Frequent short pauses allowed the debris to settle. For endoscopic use, an effective irrigation system would be essential.

The observed decline in power output from the fibretip after prolonged lithotripsy was not a practical problem. Restoration of power output as described above was quick and simple.

Our study confirms that the chemical content of stones does not seem to influence fragmentability. Large stones are relatively more fragmentable, suggesting that the technique is especially suitable for large stones. Increasing pulse energy decreases fragmentation effort. Significant mucosal damage was seen only with the higher energy settings, however, suggesting that as pulse energy increases there is an increased risk of significant ductal damage. We would therefore prefer to err on the side of caution and advise that this laser was used in vivo with visualisation. A dual lumen endoscopic catheter/basket system would seem particularly suitable.

The high capital cost of laser systems has often acted as a deterrent to their wider use. The holmium laser has shown promise for both peripheral and coronary laser angioplasty. ${ }^{13-15}$ It may become the laser of choice for long segment laser angioplasty. ${ }^{16}$ It has also been investigated for a variety of surgical applications. ${ }^{7-19}$ The cost of purchasing this laser might therefore be distributed amongst several departments. Moreover its price (approximately $£ 90000$ in the UK) compares well with comparable pulse dye lasers (approximately $£ 80-120000$ in the UK personal communication APC Cardiological, Sheffield).

Portions of this work were presented at the 50th Annual Congress of the British Institute of Radiology 1992 and pubCongress of the British
lished in abstract form.

1 van Leeuwen TG, van der Veen MJ, Verdaasdonk RM, Borst C. Tissue ablation by holmium-YSGG laser pulses through saline and blood. SPIE Laser-Tissue Interaction II 1991; 1427: 214-9.

2 Murray A, Basu R, Fairclough PD, Wood RFM. Gallstone lithotripsy with the pulsed dye laser: in vitro studies. $B r \mathcal{F}$ lithotripsy with the puls
Surg 1989; 76: 457-60.

3 Ell Ch, Hochberger J. Laser lithotripsy of common bile duct stones. In: Dixon JA, ed. Surgical applications of lasers. 2nd ed. Chicago: Year Book Publishers, 1982: 313-23.

4 Nishioka N, Levins PC, Murray SC, Parrish JA, Anderson RR. Fragmentation of biliary calculi with tunable dye lasers. Gastroenterology 1987; 93: 250-5.

5 Ell Ch, Wondrazek F, Frank F, Hochberger J, Lux G, Demling L. Laser induced shockwave lithotripsy of gallstones. Endoscopy 1986; 18: 95-6.

6 Ell Ch, Hochberger J, Muller D, Zirngibl J, Giedl J, Lux G, Demling L. Laser lithotripsy of gallstones by means of a pulsed neodynium-YAG laser - in vitro and animal experpulsed neodynium-YAG laser - in
iments. Endoscopy 1986; 18: 92-4.

7 Ponchon T, Gagnon P, Valette P-J, Henry L, Chavaillon A, Thieulin F. Pulsed dye laser lithotripsy of bile duct stones. Gastroenterology 1992; 100: 1730-6.

8 van Leeuwen TG, van der Veen MJ, Verdaasdonk RM, Borst C. Noncontact tissue ablation by holmium-YSGG pulses in blood. Lasers Surg Med 1991; 11: 26-34.

9 Blomley MJK, Nicholson DA, Bartal G, Bradley A, Myers M. Penetration of the holmium-YAG laser through fluids. fournal of Vascular and Interventional Radiology 1995 (in press).

10 Johnson JP, Oz MC, Chuck RSH, Treat MR. Comparison of methods for transcatheter fragmentation of gallstones. Surg Endosc 1989; 3: 7-10.

11 Spindel ML, Moslem A, Bhatia KS, Jassemejad B, Bartels $\mathrm{KE}$, Powell RC, O'Hare C, Tytle T. Comparison of holmium and flashlamp pumped dye laser for use in lithotripsy of biliary calculi. Lasers Surg Med 1992; 12: 482-9.

12 Sterenborg HJCM, van den Akker HP, van der Meulen FW, van Swol CFP, van Leeuwen AGJM, van Gemert MJC. Laser lithotripsy of salivary stones: a comparison between the pulsed dye laser and the Ho-YSGG laser. Lasers Med Sci 1990; 5: 357-63.

13 Vorwek D, Zolatas G, Hessel S, Adam G, Wondrazek F, Gunther RW. In vitro ablation of normal and diseased Gunther RW. In vitro ablation of normal and diseased vascular tissue by means of a fibre transm
laser. Invest Radiol 1991; 26 (7): 660-4.

14 Tomaru T, Geschwind HJ, Boussignac G, Lange F, Tahk $\mathrm{SH}$. Comparison of ablation efficiency of excimer, pulsed dye and holmium-YAG lasers relevent to shock waves. Am Heart $\mathcal{F}$ 1992; 123 (4:1): 886-95.

15 Kopchok GE, White RA, Tabbara M, Saadatmanesh V, Peng S-K. Holmium:YAG laser ablation of vascular tissue. Lasers Surg Med 1990; 10 (5): 405-13.

16 Rees MR. The use of lasers in interventional radiology. RAD Magazine 1991; 17 (195): 21-21.

17 Oz MC, Bass LS, Popp HW, Chuck RS, Johnson JP, Trokel SL, Treat MR. In vitro comparison of thulium-holmiumchromium:YAG and argon ion lasers for welding of biliary chromium:YAG and argon ion lasers for

18 Nishioka NS, Domankevitz Y, Flotte TJ, Anderson RR. Ablation of rabbit liver, stomach and colon with a pulsed holmium laser. Gastroenterology 1989; 96: 831-7.

19 Borirakchanyavat S, Puliafito CA, Kliman GH, Margolis TI, Galler EL. Holmium-YAG laser surgery on experimental vitreous membranes. Arch Ophthalmol 1991;109 (1): 1605-9. 